\title{
Forecasting and communication key elements for low-cost fluvial flooding early warning system in urban areas
}

\author{
Melisa Acosta-Coll ${ }^{1}$, Andres Solano-Escorcia ${ }^{2}$, Lilia Ortega-Gonzalez ${ }^{3}$, Ronald Zamora-Musa ${ }^{4}$ \\ 1,2,3 Engineering Department, Universidad de la Costa, Colombia \\ ${ }^{4}$ Engineering Department, Universidad Cooperativa de Colombia, Colombia
}

\begin{tabular}{l} 
Article Info \\
\hline Article history: \\
Received Sep 8, 2020 \\
Revised Mar 19, 2021 \\
Accepted Mar 31, 2021 \\
\hline Keywords: \\
Disemination \\
Early warning system \\
Fluvial flooding \\
Forecasting \\
LoRaWAN \\
Zigbee
\end{tabular}

\begin{abstract}
Fluvial flooding occurs when a river overspills its banks due to excessive rainfall, and it is the most common flood event. In urban areas, the increment of urbanization makes communities more susceptible to fluvial flooding since the excess of impervious surfaces reduced the natural permeable areas. As flood prevention strategies, early warning systems (EWS) are used to reduce damage and protect people, but key elements need to be selected. This manuscript proposes the monitoring instruments, communication protocols, and media to forecast and disseminate EWS alerts efficiently during fluvial floods in urban areas. First, we conducted a systematic review of different EWS architectures for fluvial floods in urban areas and identified that not all projects monitor the most important variables related to the formation of fluvial floods and most use communication protocols with high-energy consumption. ZigBee and LoRaWAN are the communication protocols with lower power consumption from the review, and to determine which technology has better performance in urban areas, two wireless sensor networks were deployed and simulated in two urban areas susceptible to fluvial floods using Radio Mobile software. The results showed that although Zigbee technology has better-received signal strength, the difference with LoRAWAN is lower than $2 \mathrm{dBm}$, but LoRaWAN has a better signal-to-noise ratio, power consumption, coverage, and deployment cost.
\end{abstract}

This is an open access article under the CC BY-SA license.

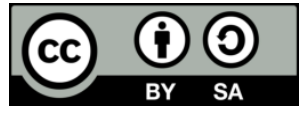

\section{Corresponding Author:}

Melisa Acosta-Coll

Engineering Department

Universidad de la Costa

Calle 58 \# 55 - 66, Barranquilla, Atlántico, Colombia

Email: macosta10@cuc.edu.co

\section{INTRODUCTION}

In the 21st century, floods have affected most people in the world and it represents approximately $47 \%$ of all climate-related disasters since 1995 [1], [2]. The period 2008-2017 recorded 348 natural disasters with 153 flood events; however, 2018 was a standout year with 127 flood events recorded. Figure 1 compares the recorded natural disasters from 2008-2017 and those reported in 2018.

The most common flood event is fluvial floods and triggering severe economic and human losses. Fluvial (river flood) or riverine flooding occurs when a river overspills its banks due to excessive rainfall [3], [4]. The World Resources Institute (WRI), with four Dutch research organizations, developed the Aqueduct Global Flood Analyzer tool that estimates current and future potential exposed to urban populations in most countries and major river basin in the world [5]. They studied and ranked 164 countries that are affected by river floods every year. They selected the 15 most-affected countries and they are all considered developed or developing countries. The Asian continent is the most affected by river floods, and India is the country with 
the highest percentage of people exposed to these disasters. Figure 2 illustrates the 15 countries most exposed to river floods worldwide according to WRI.

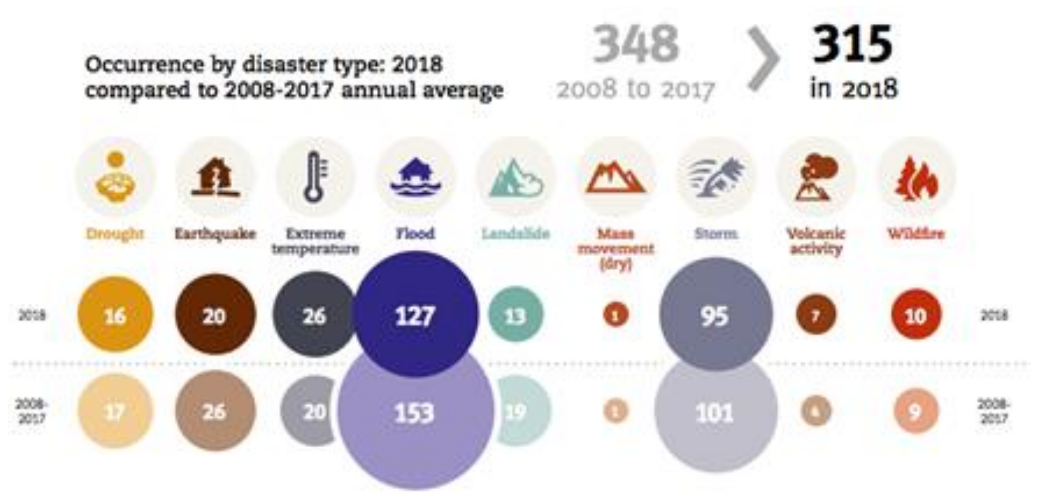

Figure 1. Numbers of natural disasters from 2008 to 2018 [6]

In urban areas, the rapid and unplanned urbanization is the primary cause of fluvial floods frequency increment during massive rainfall events [7], [8]. The excess of impervious surfaces reduced the natural permeable areas and changed the hydrologic and hydraulic watershed's response to precipitation that leads to the increment of runoff volumes and peak discharges [9]. Floods in urban areas represent one of the most significant challenges to human security and sustained economic growth, as the population during the period 2017-2050 is expected to increase by around 20\%-30\% and two-thirds of the population that live in the cities [10].

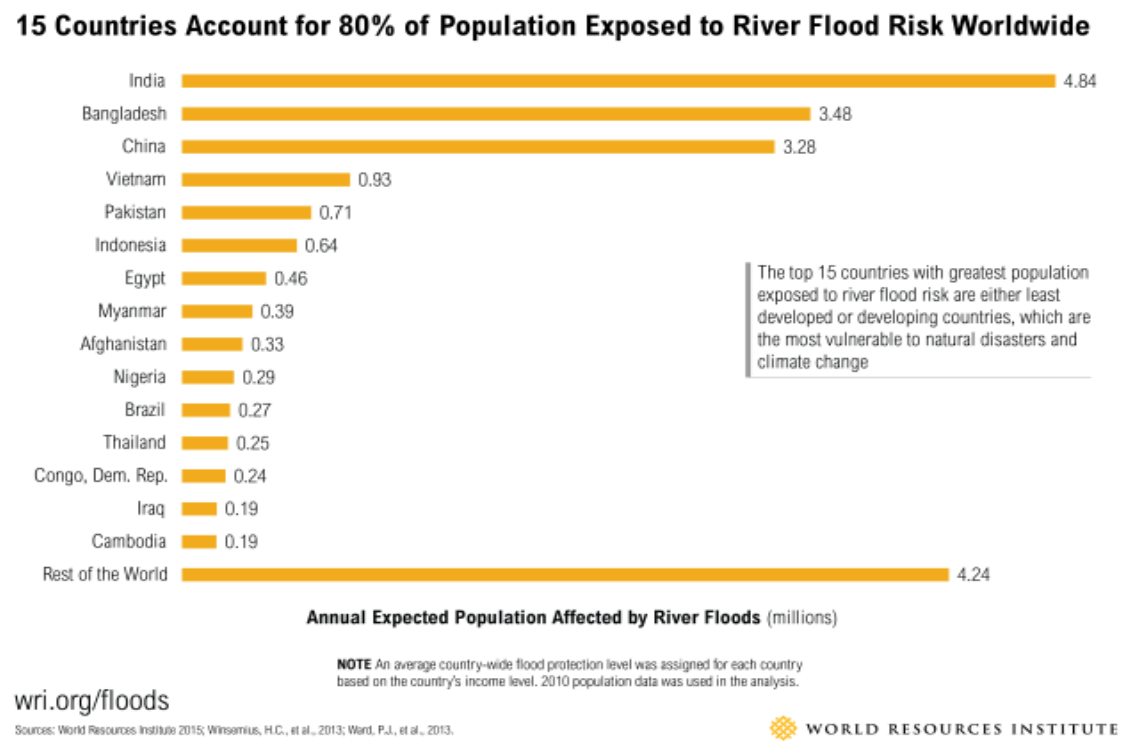

Figure 2. Most affected countries by fluvial floods [6]

There is a difference in urbanization impact between developing countries and developed countries. In developing countries, urban growth often occurs rapidly in large spaces such as entire cities; on the contrary, in developed countries, urban growth is done on a small scale and controlled. They also use technology for dynamic control within the urban environment [11]. To mitigate the risk of human losses and economic damages caused by river floods in urban areas, the International strategy for disaster reduction (ISDR) considered EWS a non-structural measure suitable for populations without enough resources to minimize the risk of flooding or implement structural solutions [2]. 
According to the World Meteorological Organization (WMO) and ISDR, an effective EWS has four main processes: Disaster risk knowledge, forecasting, dissemination-communication and preparednessresponse [2], [12]. Disaster risk knowledge identifies hazards, the exposure, vulnerabilities, and risks of a population; the forecasting process involves the monitoring and information process [13]. This process defines and implements the technology to measure meteorological and hydraulic variables, and analysis of acquired data. Dissemination-communication guarantees the sending of alerts and that they are received and understood. Finally, preparedness-response involves the activities and policies implemented in a community that allows them to react timely in a disaster event [14].

This manuscript proposes the monitoring instruments and communication protocols that guarantee the process of forecasting and disseminating alerts from an EWS efficiently during fluvial floods in urban areas. Different EWS for fluvial floods in urban areas worldwide were reviewed and compared to the variables, sensors, and communication protocols classifying into main and complementary instruments. It was identified that not all projects monitor the most important variables related to the formation of fluvial floods and the most used communication protocols with high-energy consumption. Likewise, ZigBee and LoRaWAN are the communication protocols with lower power consumption from the review, therefore, to determine which technology has better performance in terms of communication (link profile, low power consumption, and lower cost), two wireless sensor networks (WSN) were deployed and simulated in two urban areas susceptible to fluvial floods using radio mobile software. The results showed that that Zigbee technology has better-received signal strength (RSS), but LoRaWAN is the most suitable for both cases due to has better signal-to-noise ratio, power consumption, and deployment cost.

\section{METHOD}

As a first step, this research conducted a literature review to identify the primary and complementary instruments to measure the variables related to fluvial floods, the methods for information processing and the most used means for the dissemination of alerts. IEEE, ACM and Science Direct digital libraries were consulted to select data ranging from 2010 to 2020. Table 1 shows the search string limiting the information found, inclusion and exclusion criteria.

Table 1. Search string, criteria for inclusion and exclusion

\begin{tabular}{ccc}
\hline Search String & Inclusion Criteria & Exclusion Criteria \\
\hline $\begin{array}{c}\text { Flood Warning OR Early Flood Warning System } \\
\text { Fluvial Floods Warning System AND River } \\
\text { Flood Early Warning }\end{array}$ & $\begin{array}{c}\text { Research articles, books, conference } \\
\text { papers, reports from government } \\
\text { agencies, articles in English and Spanish }\end{array}$ & $\begin{array}{c}\text { Results that are not related to the } \\
\text { topic, articles other than in English } \\
\text { and Spanish }\end{array}$ \\
\hline
\end{tabular}

Ten architectures developed in different locations worldwide were selected to alert the community about the risk of fluvial flooding in urban areas. Each architecture describes the methods and instruments used to monitor and analyze in real-time the meteorological and hydraulic variables related to river floods, as well as the methods to send the alert. A comparative analysis was carried out and identified the key elements, main and complementary, for the forecasting and dissemination process.

Since the reviewed projects used different communication protocols, as a second step, we selected the technologies with the lowest power consumption to send the acquired data to a data processing center and compared them in terms of transmission parameters, coverage, performance, energy consumption, and costs using radio mobile software. This software uses the irregular terrain model (ITM) or the Longley-Rice model to predict radio signals'attenuation in the frequency range of $20 \mathrm{MHz}$ to $20 \mathrm{GHz}$ [15].

From the review, Zigbee and LoRaWAN are the communication protocols with the lowest power consumption. To identify which of the two technologies is more suitable for fluvial floods early warnings in urban areas, we performed a simulation of two different systems for two riverside municipalities (Malambo and Palmar de Varela) in Colombia affected annually by fluvial floods of Magdalena River [16]. For both areas, a network with Zigbee and another with LoRaWAN were designed; each network has three nodes and a central station to cover the affected study area. Figure 3(a) and 3(b) presents a map with the sensor networks, nodes location, and the distance to the central stations.

The nodes and base stations are at $15 \mathrm{~m}$ above ground level and use vertical supports of different sizes to allow data transmission between the monitoring nodes and their respective network gateway. Table 2 shows each of the points and the distance between the monitoring nodes and the base station of each municipality. 


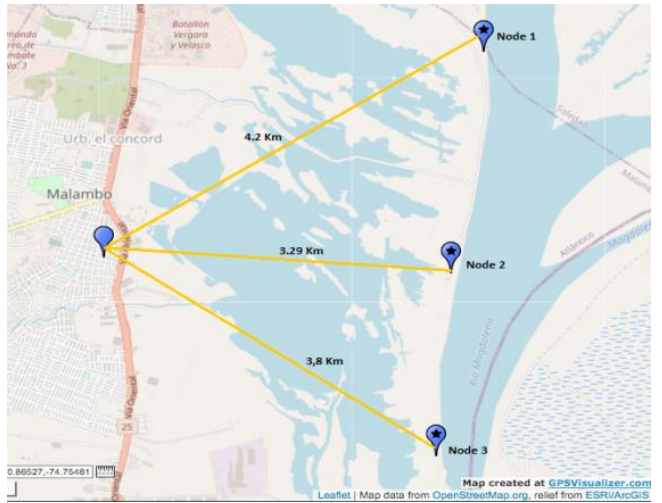

(a)

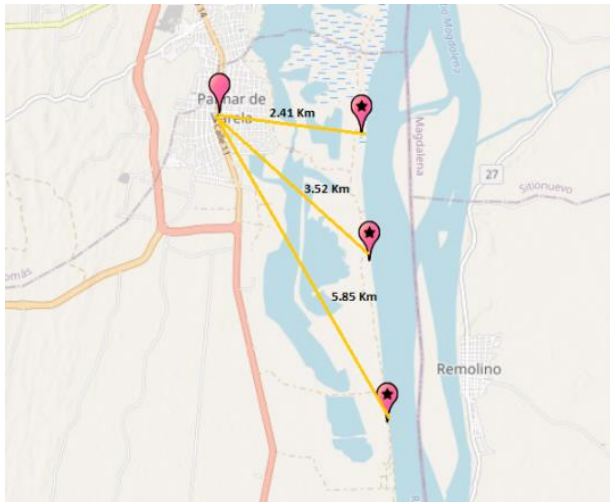

(b)

Figure 3. A map with the sensor networks, nodes location, and the distance to the central stations, (a) Malambo WSN, (b) Palmar de Varela WSN

Table 2. Location and distance of from nodes to gateway

\begin{tabular}{ccc}
\hline Point & Location & Distance from node to gateway $(\mathrm{Km})$ \\
\hline Gateway Malambo & $10^{\circ} 51^{\prime} 33.49^{\prime \prime} \mathrm{N}, 74^{\circ} 46^{\prime} 21.07^{\prime \prime O}$ & N/A \\
Node 1 - Malambo & $10^{\circ} 52^{\prime} 44.61^{\prime \prime N}, 74^{\circ} 44^{\prime} 22.35^{\prime \prime O}$ & 4,22 \\
Node 2 - Malambo & $10^{\circ} 51^{\prime} 27.97^{\prime \prime} \mathrm{N}, 74^{\circ} 44^{\prime} 32.70^{\prime \prime} \mathrm{O}$ & 3,29 \\
Node 3 - Malambo & $10^{\circ} 50^{\prime} 24.36^{\prime \prime} \mathrm{N}, 74^{\circ} 44^{\prime} 37.29^{\prime \prime} \mathrm{O}$ & 3,8 \\
Gateway Palmar & $10^{\circ} 44^{\prime} 25.58^{\prime \prime} \mathrm{N}, 74^{\circ} 45^{\prime} 18.98^{\prime \prime O}$ & $\mathrm{~N} / \mathrm{A}$ \\
Node 1 - Palmar & $10^{\circ} 44^{\prime} 13.98^{\prime \prime} \mathrm{N}, 74^{\circ} 44^{\prime} 0.42^{\prime \prime} \mathrm{O}$ & 2,41 \\
Node 2- Palmar & $10^{\circ} 43^{\prime} 5.67^{\prime \prime} \mathrm{N}, 74^{\circ} 43^{\prime} 56.27^{\prime \prime O}$ & 3,52 \\
Node 3 - Palmar & $10^{\circ} 41^{\prime} 39.18^{\prime \prime} \mathrm{N}, 74^{\circ} 43^{\prime} 46.41^{\prime \prime O}$ & 5,85 \\
\hline
\end{tabular}

\subsection{Architecture network}

The wireless sensor networks have a star topology with three monitoring nodes and a central node. The monitoring nodes have a photovoltaic system, an Arduino ONE, a rain gauge, and the selected wireless technology that sends the data to the central node. Since both WSN works in a star topology, each of the three monitoring nodes is configured as slaves and the central nodes as masters. Table 3 shows the specifications of the communication modules used in radio mobile software. Based on the review and Radio Mobile simulation results, we proposed the key elements, main and complementary, for the forecasting and dissemination process of a real-time effective early warning system for fluvial floods in urban areas.

Table 3. LoRa and zigbee devices specifications

\begin{tabular}{ccc}
\hline Wireless specifications & Dragino LoRa Shield v1.2 & Digi XBee-PRO 900HP \\
\hline Frequency band & $915 \mathrm{MHZ}$ & $902 \mathrm{a} 928 \mathrm{MHz}$ \\
Data rate & until $300 \mathrm{kbps}$ & Until $200 \mathrm{Kbps}$ \\
Line of sight & $15 \mathrm{~km}$ & $6,5 \mathrm{Km}$ \\
Transmission power & $+20 \mathrm{dBm}-100 \mathrm{~mW}$ & $+24 \mathrm{dBm}-250 \mathrm{~mW}$ \\
Receiver sensitivity & $-148 \mathrm{dBm}$ & $-101 \mathrm{dBm}$ \\
Antenna & Omnidireccional 3dBi & Dipole $2,1 \mathrm{dBi}$ \\
Voltage & 3,3 a $5 \mathrm{VDC}$ & $2,4 \mathrm{a} \mathrm{3,6} \mathrm{VDC}$ \\
Tx current & $120 \mathrm{~mA}$ & $229 \mathrm{~mA}$ \\
Rx current & $10,8 \mathrm{~mA}$ & $44 \mathrm{~mA}$ \\
Stand by current & $0,2 \mathrm{uA}$ & $3 \mathrm{uA}$ \\
\hline
\end{tabular}

\section{RESULTS AND DISCUSSION}

Below, ten architectures of EWS are described from some of the most affected countries by fluvial floods in their urban areas.

\subsection{Fluvial floods early warning system architectures \\ 3.1.1. Cagayan river basin, Philippines}

The government of the Philippines deployed more than 1,500 hydro-meteorological stations nationwide to provide real-time data for rain and flood event monitoring using two primary sensors, an 
automated rain gauge (ARG) and water level monitoring stations (WLMS) installed on bridges near the local communities [17]. For the Cagayan river basin, the Department of Science and Technology (DOST) and the Advanced Science and Technology Institute (DOST-ASTI) developed a predictive model based on the random forest algorithm to provide timely warnings of water level and flood hazard and it becomes in a decision support tool for the local communities.

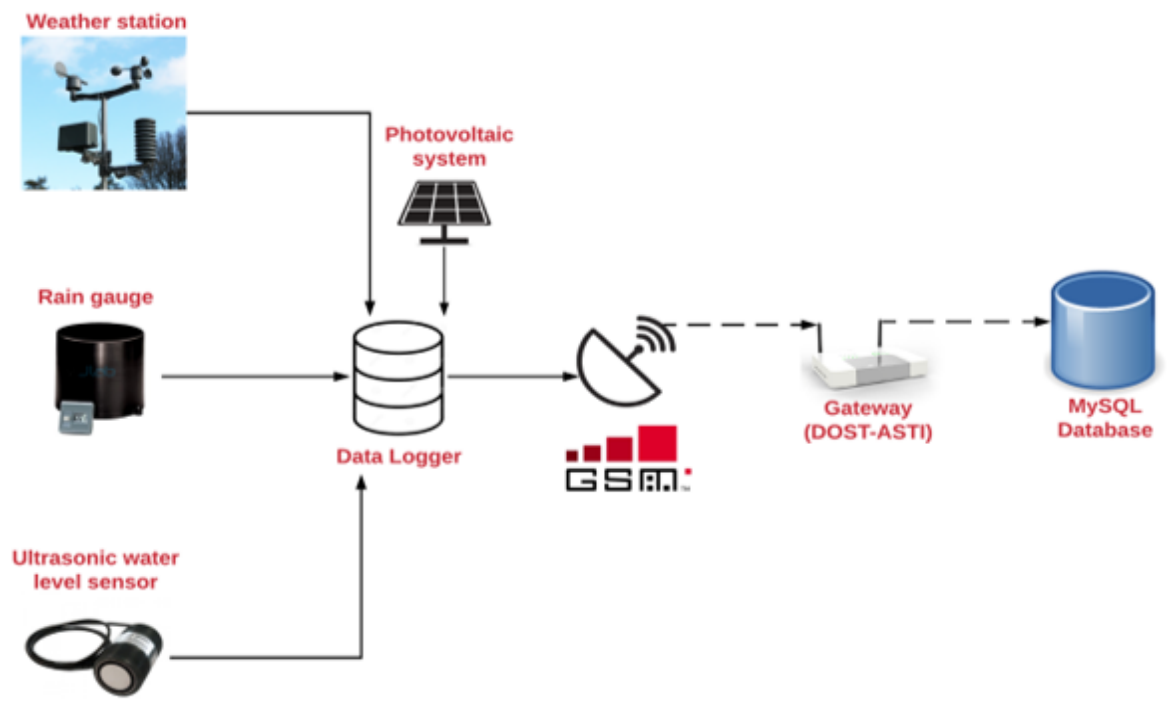

Figure 4. Cagayan river basin EWS

Besides the ARG, this predictive model integrated an ultrasonic sensor to measure water level changes in the river and a weather sensor to monitor wind speed, wind direction, air temperature, air pressure, and air humidity. The sensor data was collected by a solar-powered data logger and sent it via GSM to a GSM gateway of DOST-ASTI. Figure 4 illustrates the EWS structure.

\subsubsection{Chennai, India}

In Chennai, a city in southern India, [18] implemented a ZigBee based wireless sensor network for early flood monitoring and warning system. Each node has a water level sensor and flow level sensor and sends the acquired data to a server via a wireless ZigBee communication protocol. When the water at the dam reaches a high level, the people receive a warning message by an android application, even without network connectivity. Likewise, the application warns people to evacuate to safer zones through stored images. A significant advantage of the system is that the application can be used offline. Figure 5 illustrates the EWS structure.

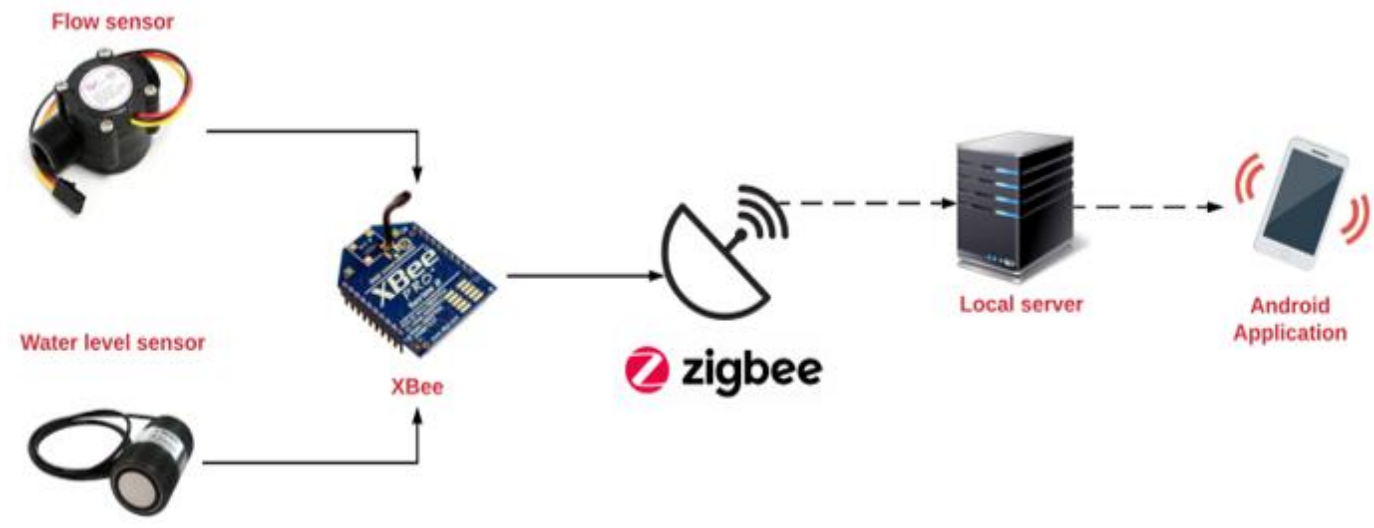

Figure 5. Chennai EWS

Forecasting and communication key elements for low-cost fluvial flooding early... (Melisa Acosta-Coll) 


\subsubsection{Tuy loan river basin, Vietnam}

The Ho Chi Minh City International University developed an early flood warning system using a mobile network. The system consists of a station powered by solar energy, a monitoring center, and a notification system. The flood warning station has a water level sensor and a rain gauge sensor that monitors water level changes in the river and rainfall. The sensors data are stored in a memory card and transmitted to the monitoring center via GPRS protocol [19].

The monitoring center receives, analyze data from the stations, and sends results to the notification system where the alarm can be generated to the considered areas. The warning message has the warning level, the measured data, and the predicted occurrence time of flooding. Likewise, a website indicates the river water level, rainfall, and the predicted information for the next few hours. Figure 6 illustrates the EWS structure.

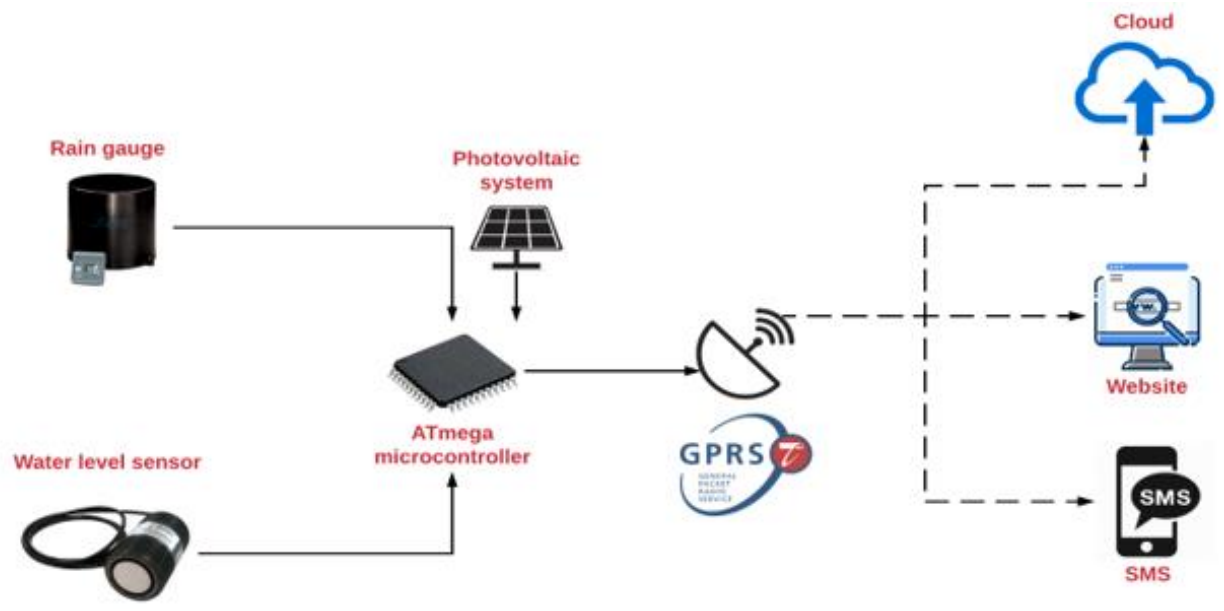

Figure 6. Tuy loan river basin EWS

\subsubsection{Bangkok, Thailand}

Dersingh presented the design and development of a flood warning system via mobile and computer networks. The system integrated a tipping bucket (rain gauge), an ultrasonic sensor, and a camera that measure the amount of rainfall, water level, and image of the surrounding area periodically. The collected data are sent to a server over the Internet via GSM/3G air card, stored on a database, and processed to determine early warning of flood in the zone [20]. After getting sensors data, the system analyzes and compares it with historical data including data of the year 2011, where the significant flood in Thailand happened. The data are used for two principal threshold criteria: the amount of rainfall in twenty-four hours and water level. If these values are equal or higher than the major flood, the system generates a warning message to the web and mobile application. Figure 7 shows the EWS structure.

\subsubsection{Northern and Western Provinces, Rwanda}

Floods commonly affect Rubavu, Nyabihu, and Musanze districts. Therefore, Vunabandi et al. proposed an innovative and inexpensive framework designed to provide early warning for natural disasters via a siren. The system has a water level detector (sensor) to monitor water level changes. It works by recording and transmitting sensor data to the server computer via ZigBee protocol [21]. The server processes the data and then gives the warning to advice vulnerable citizens before the floods come around their houses. The Arduino Uno board captures data and sends signals when the water level sensor detects the presence of a boost of water compared to the average river flow level. Lastly, an alert warning sound will be sent through siren only when the detected water level exceeds the average expectation to a hazardous water flow level on the river. It should be noted that a Wi-Fi protocol also assists real-time data transmission. The system works with solar panels. Figure 8 illustrates the EWS structure.

\subsubsection{Bangladesh}

Islam et al. designed and implemented an early warning system that provides a way to remotely supervising water levels of river stations [22]. The system has a Honeywell LL103101 water sensor, which produces a digital output that determines the presence or absence of liquid. The obtained data are sent to the 
Apache web server via Zigbee. River level data and alerts are sent through a website and SMS. To send SMS messages from the website, they used Ozeki NG SMS Gateway. The proposed system aims to register the water level every hour, show it to the supervisor, and caution the relevant authorities when the level of water exceeds a user-defined threshold. The early warning system works with a battery. Figure 9 illustrates the EWS structure.

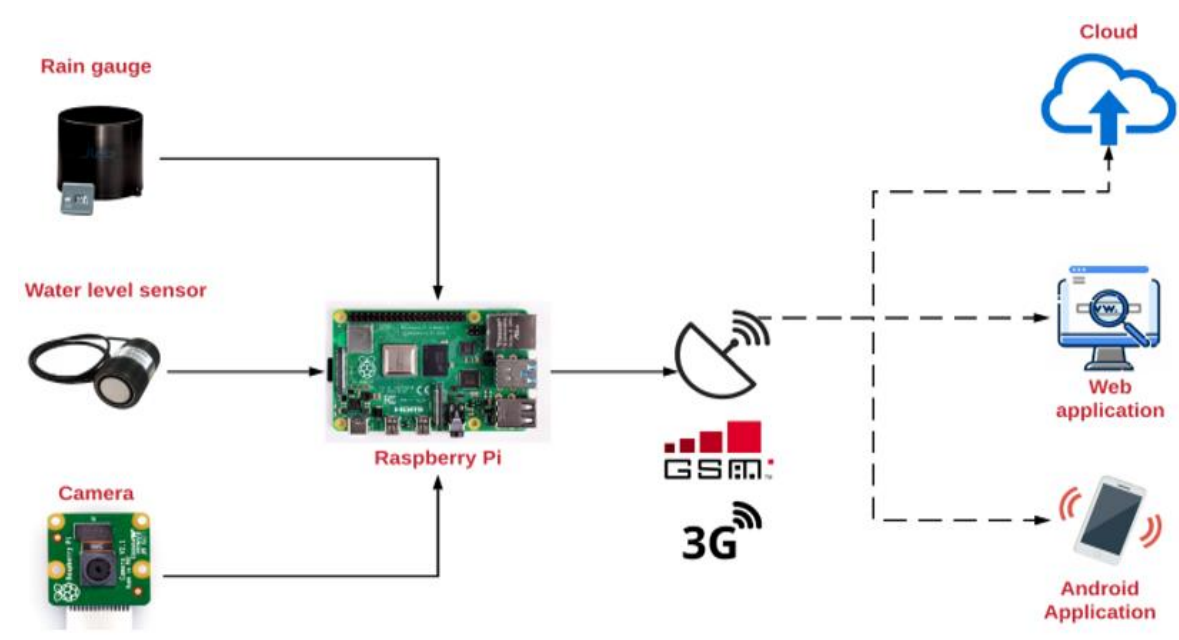

Figure 7. Bangkok EWS

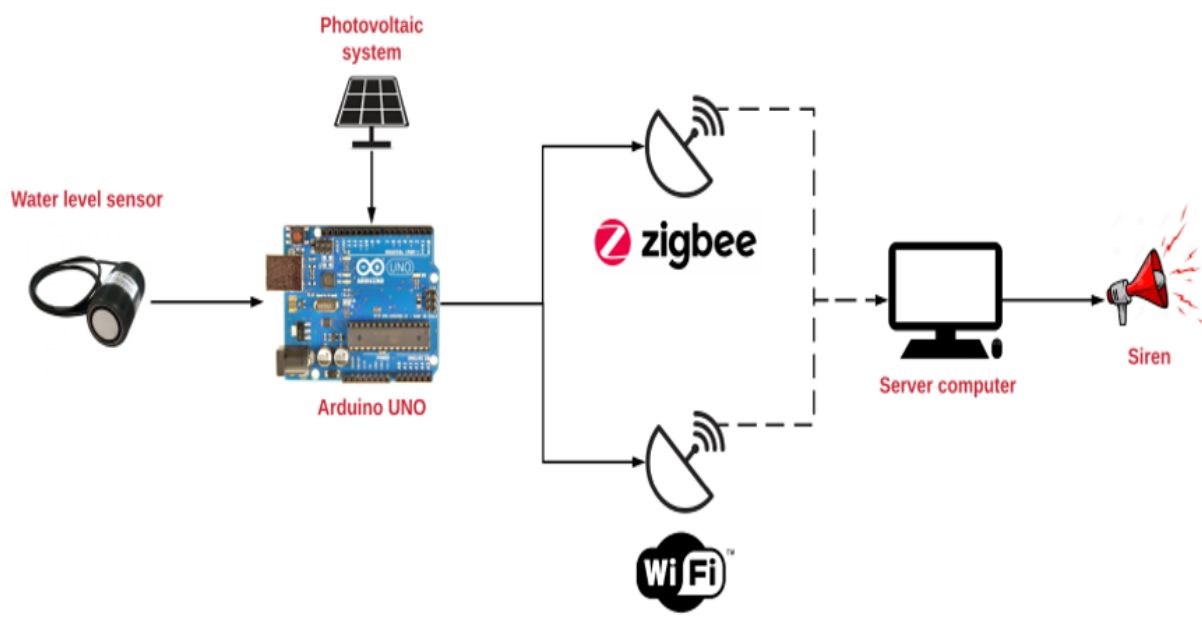

Figure 8. Rwanda EWS

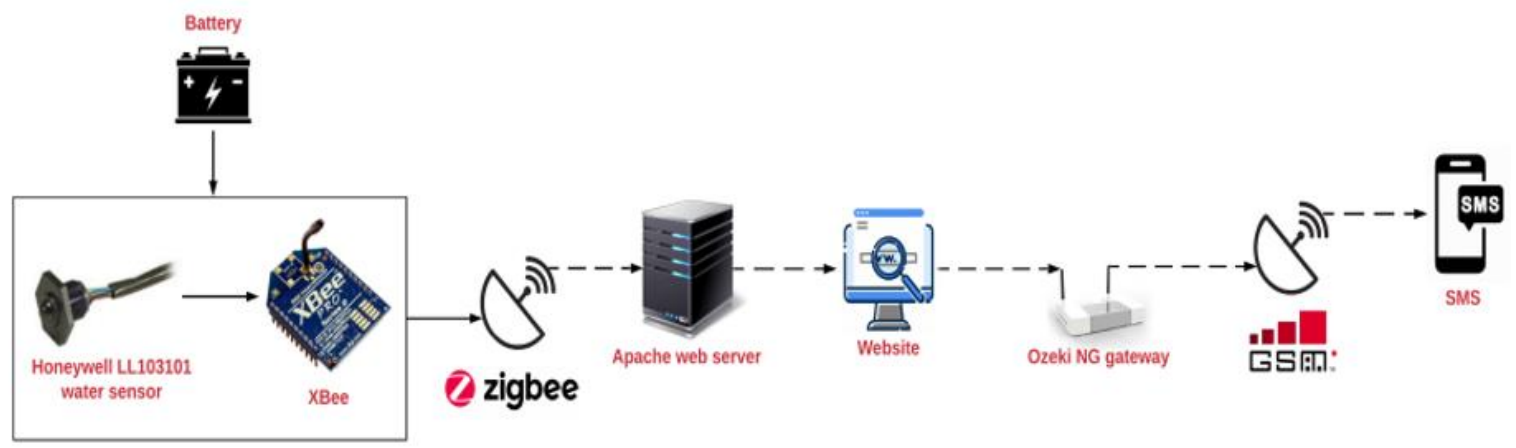

Figure 9. Bangladesh EWS

Forecasting and communication key elements for low-cost fluvial flooding early... (Melisa Acosta-Coll) 


\subsubsection{Jamshoro, Pakistan}

The Mehran University of Engineering and Technology developed a flood/drought forecasting system (FDFS) using WSN to help the Pakistani government obtain early information about flooding and drought possibilities to take timely measures [23]. The system covers 19 barrages of 27 mainstream rivers in Pakistan and comprise a mechanical buoy equipped with water level sensors in the river and weather stations to monitor wind, pressure, humidity, and water pressure. Furthermore, the system uses ZigBee between the sensor and the coordinator and then uses worldwide interoperability for microwave access (WiMAX) to send the data to the internet. Figure 10 shows the EWS architecture.

\subsubsection{Tabasco, México}

Leon et al. proposed an early warning system for river overflow. The network consists of an ultrasonic water level sensor that measures the distance between the sensor and the water mass. The TTGO microcontroller processes the sensors data. The collected data are sent to a Raspberry Pi 3B + via LoRa [24]. The raspberry pi keeps the data on a database and in the same way, the data will be published in a Twitter account. Figure 11 illustrates the EWS structure.

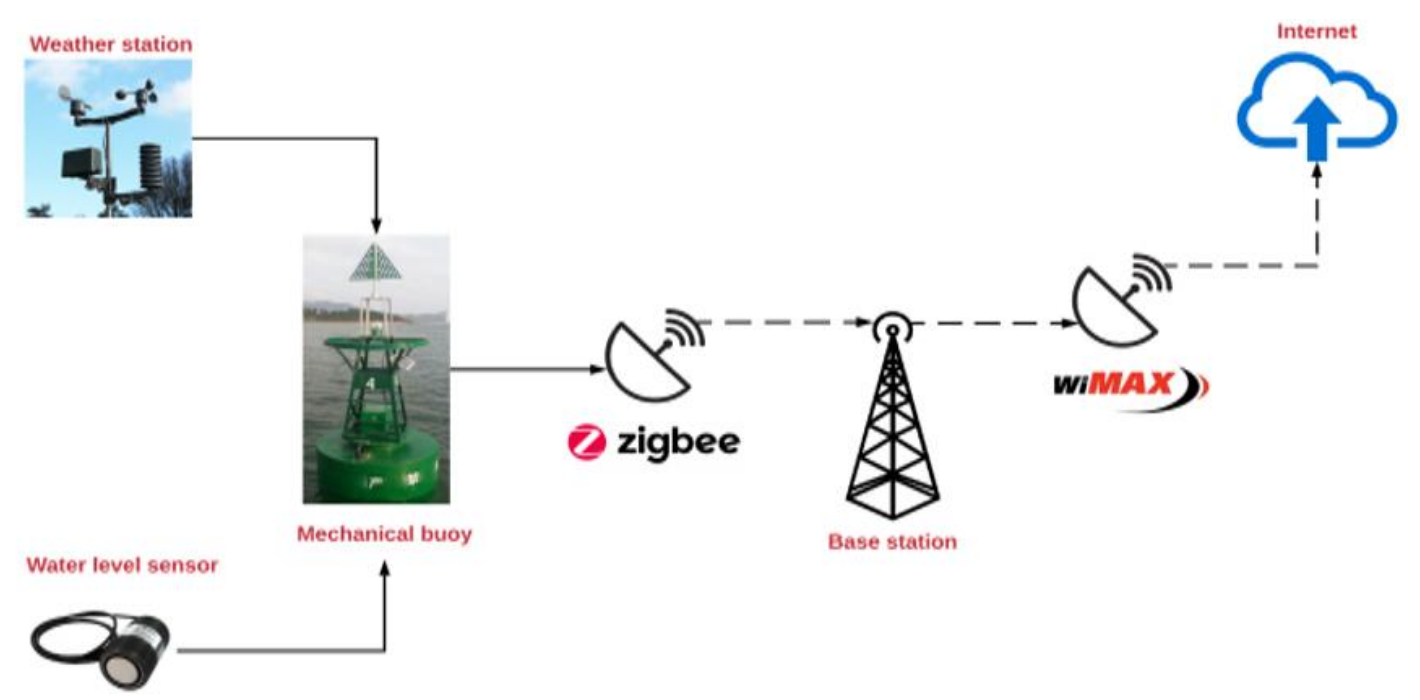

Figure 10. Jamshoro EWS

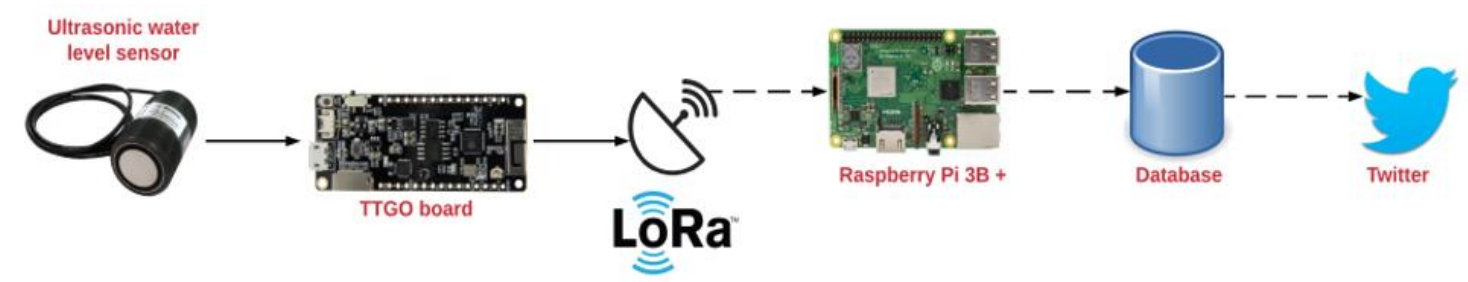

Figure 11. Tabasco EWS

\subsubsection{Manzanares River basin, Colombia}

Guillot et al. developed an early warning system that predicts possible floods in the Manzanares River basin in Santa Marta, Magdalena [25]. The system incorporates a rain gauge, a radar level sensor, soil moisture, and an Arduino MEGA 2560 that processes the data. A data logger collects the acquired data and sends it to a local server via GPRS. If the mobile network fails, the backup protocol (Zigbee) will transmit the acquired environmental measurements. The information on a possible flood is sent to a mobile application, which employs a prediction model to issue three types of alerts: yellow, orange, and red. These alerts are visible to the community members and entities belonging to the emergency operations center of the Santa Marta District. Furthermore, the system sends river levels via SMS. Figure 12 illustrates the EWS structure. 


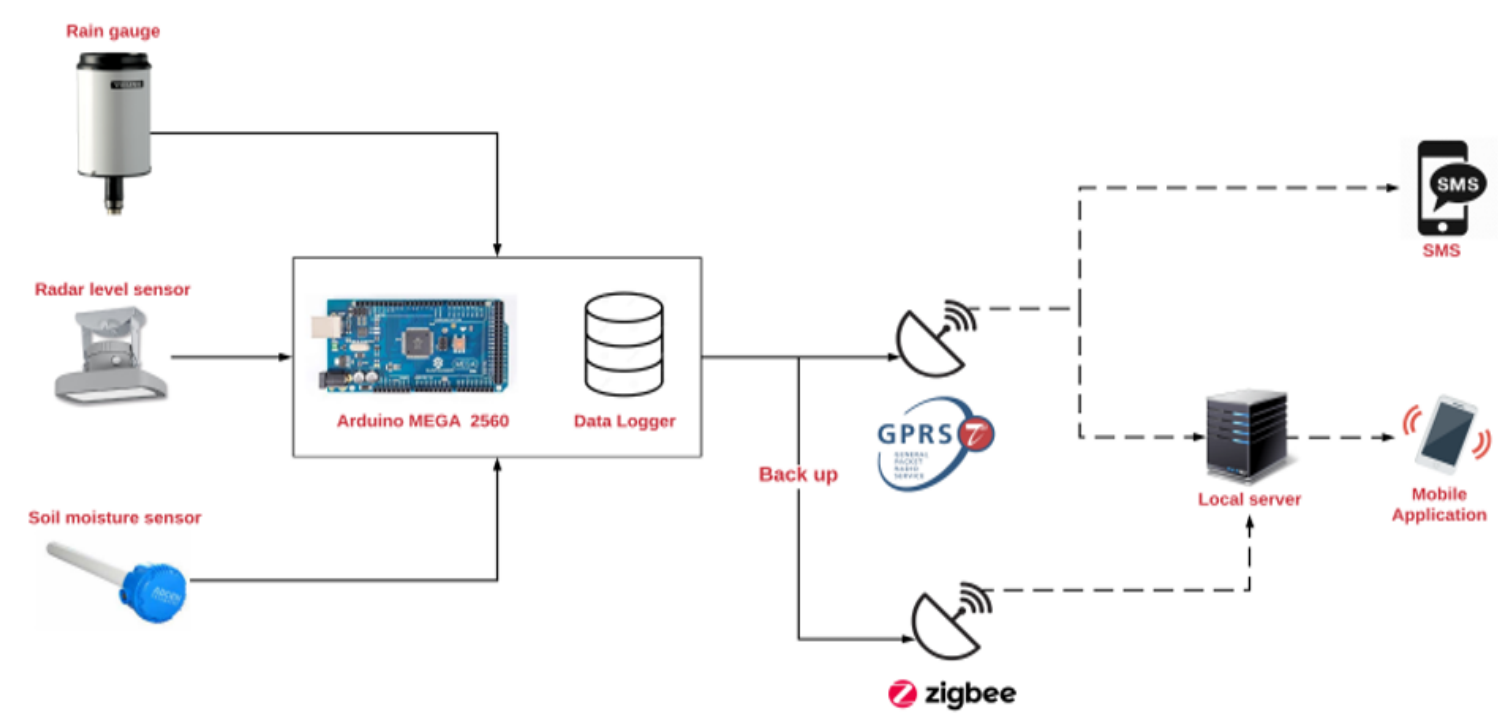

Figure 12. Manzanares river basin EWS

\subsubsection{Negro and Tobia river basins, Colombia}

An EWS integrated with s a weather station and an ultrasonic water level sensor powered by solar panels monitors the Negro and Tobia rivers in Colombia [26]. The system uses a microcontroller to process the data and a LoRa communication module to send it to a web server. The alert will reach Tobia's fire station and the information will be available in the cloud through an application that generates another alert to the population. Figure 13 shows the EWS.

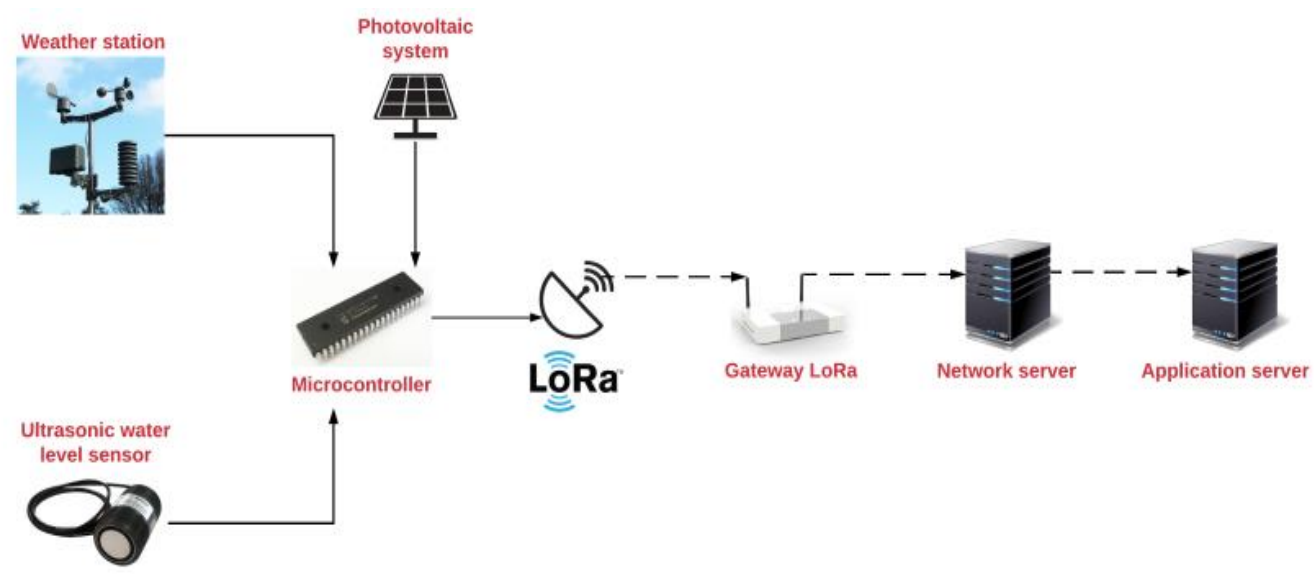

Figure 13. Negro and Tobia river basins EWS

Table 4 summarizes the monitoring instruments implemented in the projects mentioned above to measure the variables related to the formation of fluvial floods in urban areas. Likewise, Table 4 shows the communication protocols to send sensors' data, where do they process the data, the alert dissemination methods, if the information is available online, and the power supply system. All the reviewed projects focused their early warning system design on the forecasting and alert dissemination processes.

From the reviewed projects, all of them considered the water level as the primary variable to monitor and can be classified into submergible and ultrasonic sensors. The submergible sensors are pressure sensors that measure the uniform weight of a column and translate it to level measurement. Conversely, ultrasonic sensors are non-submergible sensors that send a sound wave to the water and measure the water level by calculating the sound wave's sending and receiving time.

Besides the water level sensor, three of the reviewed projects used a rain gauge to measure the precipitation, and the others used other complementary instruments such as flow meter, weather stations, and

Forecasting and communication key elements for low-cost fluvial flooding early... (Melisa Acosta-Coll) 
an anemometer. Only one project implemented a camera to record the river conditions. Considering the communication protocol, most of the reviewed projects used one protocol to send the acquired data and the most used are Zigbee and GPRS. Only two projects have a backup protocol in case the main protocol fails. Table 5 compares the project protocols in terms of nominal range and transmitted power.

Table 4. Review summary

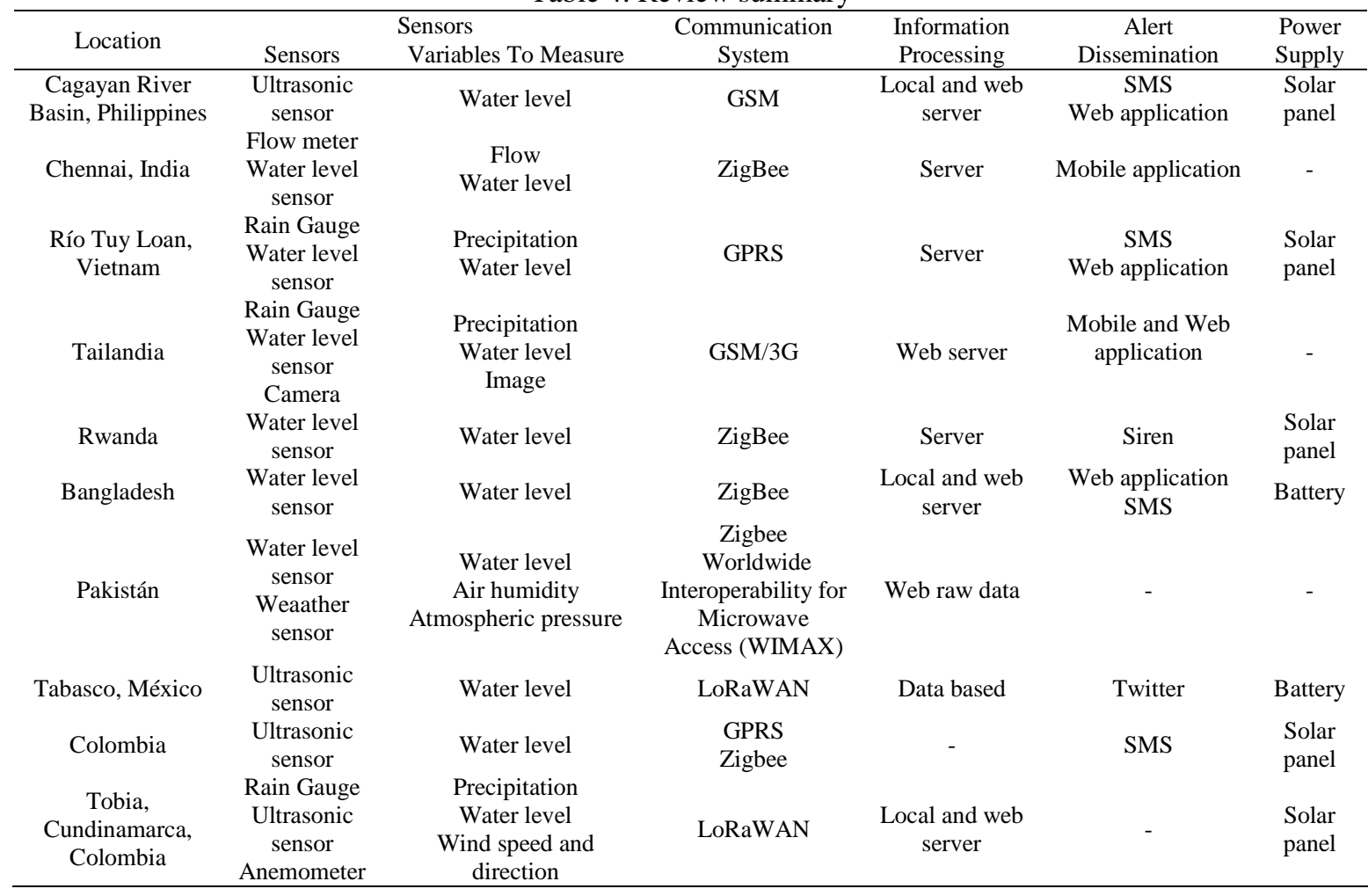

Table 5. Communication protocols comparison

\begin{tabular}{cccccc}
\hline Protocols & ZigBee/IP & Wi-Fi & Wi-Max & GSM/GPRS & LoRaWAN \\
\hline $\begin{array}{c}\text { Nominal range } \\
(\mathrm{km})\end{array}$ & $0.01-1$ & $0.01-0.1$ & $0.3-49$ & $2-35$ & $\begin{array}{c}5-15 \mathrm{~km}(\mathrm{urban}) \\
\text { (rural) }\end{array}$ \\
$\begin{array}{c}\text { Transmitted } \\
\text { Power (W) }\end{array}$ & 0.1 & $0.8-1$ & 0.25 & 2 km (LOS) \\
\hline
\end{tabular}

According to Table 5, Zigbee and LoRaWAN have lower transmitted power and GPRS is the protocol with higher power consumption. However, GPRS has a better nominal range, therefore better coverage. This is the main reason for which LoRa has been widely used in IoT applications [27]. About power supply, most of the projects use a photovoltaic system; others are connected to the grid and have batteries in case of power supply failure. All the reviewed EWS sends the acquired data to a local or web server for processing the measurements and create the alerts. The preferred mains to communicate the alerts to the risk population are web applications and SMS; only one project used a social network like Twitter and one project used a sound alert.

\subsection{RF propagation simulation}

From Table 5, Zigbee and LoRaWAN are the communication protocols with lower power consumption; for this reason, they are being widely used to deploy sensor networks. To identify the most suitable protocol to send timely alerts for fluvial floods in urban areas, these technologies were compared using radio mobile software, simulating two WSN in two riverside municipalities affected by fluvial floods in Colombia, Malambo and Palmar de Varela. Following, Tables 6 and 7 present the radio link profile of Malambo WSN and Palmar de Varela WSN with the path loss and RSSI measurements for each radio link. 
Table 6. Malambo WSN radio link profile

\begin{tabular}{cccccc}
\hline \multirow{2}{*}{ Radio Link } & \multirow{2}{*}{ Distance $(\mathrm{Km})$} & \multicolumn{2}{c}{ PathLoss $(\mathrm{dB})$} & \multicolumn{2}{c}{ Received Signal Strengh Indicator } \\
& & LoRaWAN & Zigbee & LoRaWAN & Zigbee \\
\hline Node 1 - Gateway & 4,22 & 104,1 & 104,1 & $-78,4$ & $-76,3$ \\
Node 2 - Gateway & 3,29 & 101,9 & 102 & -78 & -76 \\
Node 3 - Gateway & 3,8 & 103,2 & 103,2 & $-85,9$ & $-84,3$ \\
\hline
\end{tabular}

Table 7. Palmar de varela WSN radio link profile

\begin{tabular}{cccccc}
\hline \multirow{2}{*}{ Radio Link } & \multirow{2}{*}{ Distance $(\mathrm{Km})$} & \multicolumn{2}{c}{ PathLoss $(\mathrm{dB})$} & \multicolumn{2}{c}{ Received Signal Strengh Indicator } \\
& & LoRaWAN & Zigbee & LoRaWAN & Zigbee \\
\hline Node 1 - Gateway & 2,41 & 99,2 & 99,3 & $-75,4$ & $-73,4$ \\
Node 2 - Gateway & 3,52 & 102,5 & 102,6 & $-77,5$ & $-75,4$ \\
Node 3 - Gateway & 5,85 & 106,9 & 107 & $-82,9$ & $-80,8$ \\
\hline
\end{tabular}

In Malambo, the radio links between the monitoring nodes and the gateway showed a path loss for both technologies between 102-104 dB and for Palmar de Varela between 99-107 dB. The above is because the municipality of Palmar de Varela has a lower population density rate and more cleared areas. Considering the RSSI, Zigbee technology presented a better performance than LoRaWAN. This is because Zigbee modules transmit up to $+24 \mathrm{dBm}$ compared to the maximum transmit power of LoRaWAN devices, which is $+20 \mathrm{dBm}$. However, the measurement difference between both technologies is not as significant in each radio link.

\subsection{Devices costs}

An important parameter to consider when implementing a WSN is cost. Table 8 shows the costs per device for Zigbee and LoRa technology used for the simulation. From Table 8, Zigbee technology devices are more expensive than LoRa devices; therefore, the implementation of LoRaWAN communication protocol to send timely alerts is more suitable for a low-cost EWS. Considering the simulation results, although Zigbee technology obtained a better RSSI than LoRaWAN, there is a low difference between each node's reception power levels, which is between 1-2.1 dBm. Likewise, considering other parameters, LoRaWAN has a low sensitivity to the noise of its equipment, it has a higher coverage range, the energy consumption is lower than Zigbee, and the cost per device. Therefore, LoRAWAN is the most suitable communication protocol for fluvial floods in urban areas.

Table 8. Cost per device for zigbee and LoRa

\begin{tabular}{ccccc}
\hline \multicolumn{4}{c}{ LoRa } & \multicolumn{2}{c}{ Zigbee } \\
Component & Device & Cost & Device & Cost \\
\hline Tx module & Dragino LoRa Shield v1.2 915MHz & $\$ 23,92$ & Digi XBee-PRO 900HP & $\$ 42,90$ \\
Antenna & Omnidirectional3dBi 915MHz & $\$ 9,89$ & Dipolo 2,1 dBi 900MHZ & $\$ 20$ \\
Gateway & Dragino LPS8 & $\$ 124,18$ & Modem XBee-PRO 900HP & $\$ 154,06$ \\
& Total & $\$ 157,99$ & Total & $\$ 216,96$ \\
\hline
\end{tabular}

Figure 14 shows the proposed primary and secondary elements of the forecasting and dissemination process for an effective fluvial flood early warning system in urban areas. It also shows the communication protocol selected from the RF simulation. From Figure 14, the central monitoring instruments for the forecasting process are the water level sensor and the rain gauge. Although the rain gauge was not the main instrument in all the reviewed projects, it is included in the proposed forecasting process since precipitation measurement is one of the main inputs for flood modeling in urban areas [28]. The weather station, flow meter, and video recording are considered complementary monitoring instruments.

The review showed that GPRS and Zigbee are the most used communication protocols; however, GPRS has a higher power consumption, it needs a more complex photovoltaic system that will increase the deployment cost; likewise, it depends on the mobile services costs. Since Zigbee and LoRaWAN have the lowest power consumption, we compared them in terms of RSSI, coverage, S/N ratio, power consumption, and costs o determine which technology has better performance. From the results, Zigbee has better RSSI than LoRaWAN, but the difference is low. Due to LoRa has lower consumption, the devices are cheap, have higher coverage, and better $\mathrm{S} / \mathrm{N}$ ratio, it was selected as the primary communication protocol and it is suggested to use Zigbee as a backup protocol in case of failures. The acquired data is sent to a web or local server to process the information and create the alerts to send them to the risk population.

Forecasting and communication key elements for low-cost fluvial flooding early... (Melisa Acosta-Coll) 


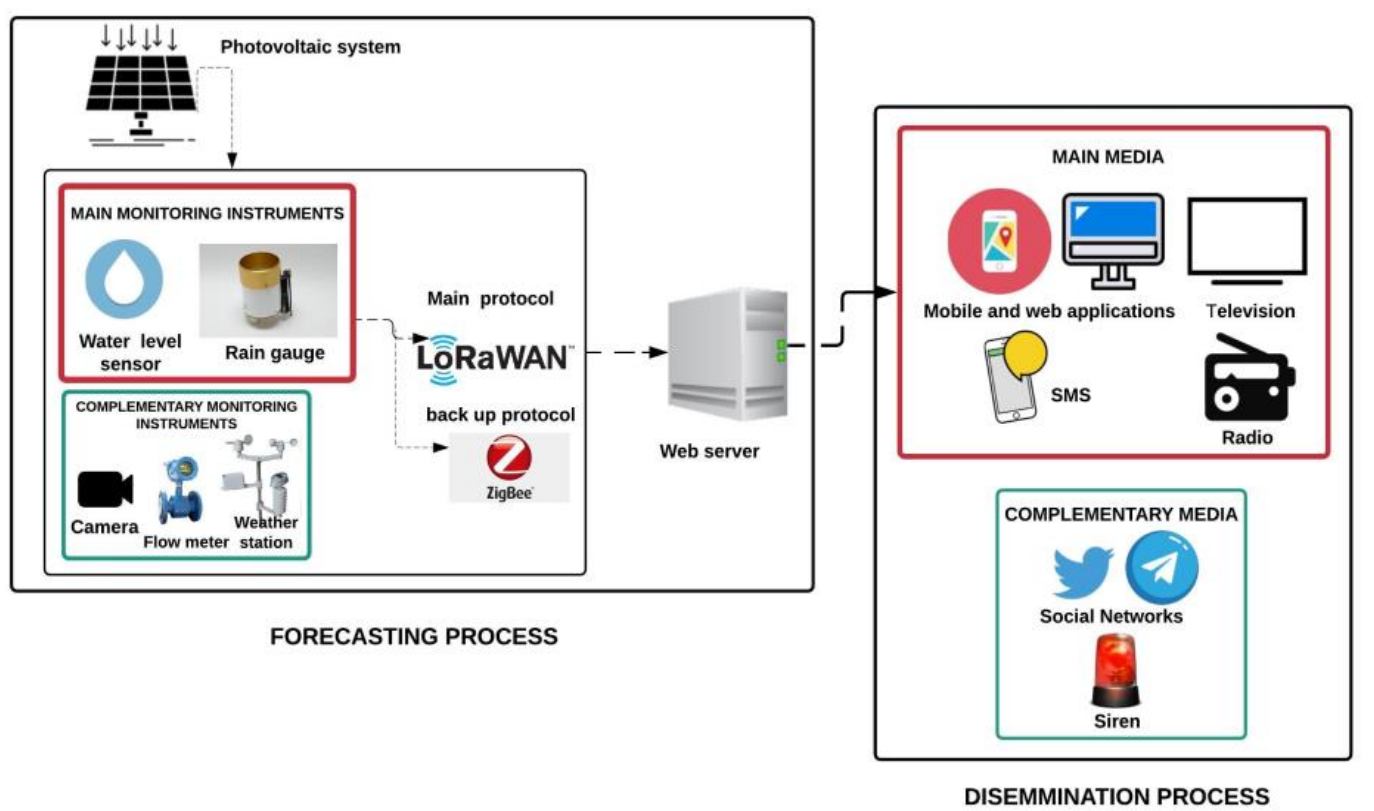

Figure 14. Proposed key elements for forecasting and dissemination process

About the dissemination process, from the review, the most used media were mobile and web applications, as well as short message service (SMS). However, a survey carried out to Hong Kong residents which are considered to be one of the safest cities in the world today, showed that the preferred media for disaster alert dissemination are television (52\%), Facebook (18,9\%), WhatsApp (9.6), radio (8.2\%), news agency websites (6.1\%) and government websites (2.9\%) [29], thus, television and radio were included as main media for alert dissemination. Social networks and sound alerts like sirens are complementary media. It is suggested to use Twitter and telegram since allow easy and free linking with different platforms.

\section{CONCLUSION}

This research performed a systematic review and a Radio Frequency simulation to determine the key elements of the forecasting and dissemination process for an effective early warning system (EWS) for fluvial floods in urban areas. For the forecasting process, the systematic review showed that the most used instrument for monitoring is the water level sensor, that we can find them of two types, ultrasonic and pressure. However, there are radar water level sensors, which external agents less affect their signal, but they are more expensive. On the other hand, in addition to the level sensor, some reviewed projects used rain gauge for precipitation measurement that is a vital input for flood modeling in urban areas; therefore, it is considered central monitoring. Other monitoring instruments such as weather stations, flow meter, and camera for video recording are considered as complementary monitoring instruments.

Likewise, the review showed that Zigbee and GPRS are the preferred communication protocol to send the acquired data to the data center for information processing; however, GPRS has high power consumption and the cost is high over time. The protocol with lower power consumption is LoRaWAN and to determine which technology has better performance, we compared LoRaWAN and Zigbee in terms of RSSI, coverage, $\mathrm{S} / \mathrm{N}$ ratio, power consumption, and costs by an RF simulation.

Using Radio Mobile software, two WSN for two urban municipalities in Colombia affected by Magdalena River floods were deployed. In each municipality, it was simulated a WSN Zigbee and another with LoRaWAN, with three monitoring nodes and a gateway for each one. The simulation results showed that Zigbee has better RSSI than LoRaWAN, but the difference is low. Since LoRaWAN has lower power consumption, higher coverage, better S/N ratio, and the cost per device is cheaper than Zigbee; it was selected as the primary communication protocol and Zigbee a backup protocol in case of failures.

For the dissemination process, form the review, the leading media used to send the alerts to the risk population are web and mobile application and SMS and the complementary media are social networks and sound alerts. However, television and radio were included since they are massive; they are useful mass media for disseminating alerts. It should be noted that the channels for sending alerts must be multiple to guarantee communication with the community. 


\section{REFERENCES}

[1] CRED and UNISDR, "The Human Cost of Weather Related Disasters 1995-2015," 2015. [Online]. Available: https://www.unisdr.org/files/46796_cop21weatherdisastersreport2015.pdf.

[2] International Strategy for Disaster Reduction (ISDR), "Emerging Challenges for Early Warning Systems in context of Climate Change and Urbanization," Switzerland, 2010. [Online]. Available: http://www.preventionweb.net/ files/15689_ewsincontextofccandurbanization.pdf.

[3] J. D. Miller and M. Hutchins, "The impacts of urbanisation and climate change on urban flooding and urban water quality: A review of the evidence concerning the United Kingdom," J. Hydrol. Reg. Stud., vol. 12, pp. 345-362, 2017, doi: 10.1016/j.ejrh.2017.06.006.

[4] H. Apel, O. M. Trepat, N. N. Hung, D. T. Chinh, B. Merz, and N. V. Dung, "Combined fluvial and pluvial urban flood hazard analysis: Concept development and application to Can Tho city, Mekong Delta, Vietnam," Natural Hazards and Earth System Sciences., vol. 16, no. 4, pp. 941-961, 2016, doi: 10.5194/nhess-16-941-2016.

[5] World Resources Institute (WRI), "World's 15 Countries with the Most People Exposed to River Floods," 2015. [Online]. Available: https://www.wri.org/blog/2015/03/world-s-15-countries-most-people-exposed-river-floods.

[6] CRED, "Natural Disasters," 2015. [Online]. Available: https://www.emdat.be/.

[7] S. Bae and H. Chang, "Urbanization and floods in the Seoul Metropolitan area of South Korea: What old maps tell us,” Int. J. Disaster Risk Reduct., vol. 37, Jul., 2019, Art. No. 101186, doi: 10.1016/j.ijdrr.2019.101186.

[8] J. Du, L. Cheng, Q. Zhang, Y. Yang, and W. Xu, "Different Flooding Behaviors Due to Varied Urbanization Levels within River Basin: A Case Study from the Xiang River Basin, China," Int. J. Disaster Risk Sci, vol. 10, pp. 89-102, 2019, doi: 10.1007/s13753-018-0195-4.

[9] Y. Anker et al., "Effect of rapid urbanization on Mediterranean karstic mountainous drainage basins," Sustain. Cities Soc., vol. 51, Nov. 2019, Art. No. 101704, doi: 10.1016/j.scs.2019.101704.

[10] UNDESA, "World Population Prospects. The 2017 Revision. Key Findings and Advance Tables," United Nations Department of Economic and Social Affairs, New York, ESA/P/WP/248, 2017. [Online]. Available: https://population.un.org/wpp/Publications/Files/WPP2017_KeyFindings.pdf.

[11] S. J. McGrane, "Impacts of urbanisation on hydrological and water quality dynamics, and urban water management: a review," Hydrol. Sci. J., vol. 61, no. 13, pp. 2295-2311, 2016, doi: 10.1080/02626667.2015.1128084

[12] World Meteorological Organization, "Guidelines on Early Warning Systems and Application of Nowcasting and Warning Operations," 2010. [Online]. Available: https://library.wmo.int/doc_num.php?explnum_id=9456.

[13] M. Acosta-Coll, F. Ballester-Merelo, and M. Martinez-Peiro, "Early warning system for detection of urban pluvial flooding hazard levels in an ungauged basin," Nat. Hazards, vol. 92, pp. 1237-1265, 2018, doi: $10.1007 / \mathrm{s} 11069-018-3249-4$.

[14] M. Acosta-Coll, F. Ballester-Merelo, M. Martinez-Peiro, and E. de la Hoz-Franco, "Real-Time Early Warning System Design for Pluvial Flash Floods-A Review," Sensors, vol. 18, no. 7, 2018, Art. No. 2255, doi: $10.3390 / \mathrm{s} 18072255$.

[15] S. E. Shumate, "Longley-Rice and ITU-P.1546 Combined: A New International Terrain-Specific Propagation Model," 2010 IEEE 72nd Vehicular Technology Conference, Ottawa, Canada, 2010, pp. 1-5, doi: 10.1109/VETECF.2010.5594342.

[16] Gobernación del Atlántico, "Plan de Desarrollo 2020-2023,” Gobernación del Atlántico, Colombia, 2020. [Online]. Available: https://www.atlantico.gov.co/images/stories/plan_desarrollo/PlanDesarrollo_2020-2023-DefinitivoA1.pdf.

[17] F. C. C. Garcia, A. E. Retamar, and J. C. Javier, "Development of a predictive model for on-demand remote river level nowcasting: Case study in Cagayan River Basin, Philippines," 2016 IEEE Region 10 Conference (TENCON), Singapore, 2016, pp. 3275-3279, doi: 10.1109/TENCON.2016.7848657.

[18] V. Balaji, A. Akshaya, N. Jayashree, and T. Karthika, "Design of ZigBee based wireless sensor network for early flood monitoring and warning system," in 2017 IEEE Technological Innovations in ICT for Agriculture and Rural Development (TIAR), Chennai, 2017, pp. 236-240, doi: 10.1109/TIAR.2017.8273723.

[19] H. N. Do, M. Vo, V. Tran, P. V. Tan, and C. V. Trinh, "An early flood detection system using mobile networks," in 2015 International Conference on Advanced Technologies for Communications (ATC), Ho Chi Minh, Vietnam, 2015, pp. 599-603, doi: 10.1109/ATC.2015.7388400.

[20] A. Dersingh, "Design and development of a flood warning system via mobile and computer networks," in 2016 International Conference on Electronics, Information, and Communications (ICEIC), Danang, Vietnam, 2016, pp. 1-4, doi: 10.1109/ELINFOCOM.2016.7563023.

[21] V. Vunabandi, R. Matsunaga, S. Markon, and N. Willy, "Flood sensing framework by Arduino and Wireless Sensor Network in Rural-Rwanda," in 2015 IEEE/ACIS 16th International Conference on Software Engineering, Artificial Intelligence, Networking and Parallel/Distributed Computing (SNPD), Takamatsu, 2015, pp. 1-6, doi: 10.1109/SNPD.2015.7176210.

[22] M. A. Islam, T. Islam, M. A. Syrus, and N. Ahmed, "Implementation of flash flood monitoring system based on wireless sensor network in Bangladesh," in 2014 International Conference on Informatics, Electronics \& Vision (ICIEV), Dhaka, Bangladesh, 2014, pp. 1-6, doi: 10.1109/ICIEV.2014.6850752.

[23] F. Khan, S. Memon, I. A. Jokhio, and S. H. Jokhio, "Wireless sensor network based flood/drought forecasting system," in 2015 IEEE SENSORS, Busan, 2015, pp. 1-4, doi: 10.1109/ICSENS.2015.7370354.

[24] E. Leon, C. Alberoni, M. Wister, and J. A. Hernandez-Nolasco, "Flood Early Warning System by Twitter Using LoRa," Proceedings, vol. 2, no. 19, 2018, Art. No. 1213, doi: 10.3390/proceedings2191213. 
[25] J. D. Guillot, C. A. Robles, and J. D. Callejas, "Adquisición de Señales Ambientales para un Sistema de Alerta Temprana," Inf. Tecnológica, vol. 28, no. 5, pp. 45-54, 2017, doi: 10.4067/S0718-07642017000500007.

[26] R. Castillo and J. C. Espitia, "Caracterización de zonas de riesgo por crecientes de ríos de bajo caudal, para la implementación de un sistema de alertas tempranas (SAT) con tecnología LoRa y LoRaWAN," Inf. Tecnológica, vol. 31, no. 2, pp. 47-54, 2020, doi: 10.4067/S0718-07642020000200047.

[27] L. Kolobe, B. Sigweni, and C. K. Lebekwe, "Systematic literature survey: applications of LoRa communication," International Journal of Electrical and Computer Engineering (IJECE), vol. 10, no. 3, pp. 3176-3183, 2020, doi: 10.11591/ijece.v10i3.pp3176-3183.

[28] E. Ramirez-Cerpa, M. Acosta-Coll, and J. Velez-Zapata, "Análisis de condiciones climatológicas de precipitaciones de corto plazo en zonas urbanas: caso de estudio Barranquilla, Colombia," Rev. IDESIA, vol. 35, no. 2, pp. 87-94, 2017, doi: 10.4067/S0718-34292017005000023.

[29] R. Lam et al., "Urban disaster preparedness of Hong Kong residents: A territory-wide survey," Int J Disaster Risk Reduct, vol. 23, pp. 62-69, 2017, doi: 10.1016/j.ijdrr.2017.04.008.

\section{BIOGRAPHIES OF AUTHORS}

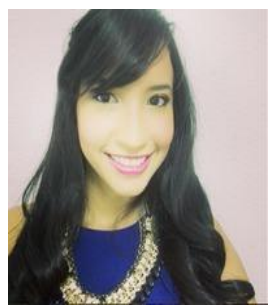

Melisa Acosta Coll is a full-time professor at Universidad de la Costa in the Computer Science and Electronic department with participation in teaching and research processes in the areas applied electromagnetics, telecommunications, bioengineering, and research methodology. His experience includes managing research projects developed in cooperation with Colombian and foreign, institutions, and universities. His outcomes include several research articles published in high impact international journals.

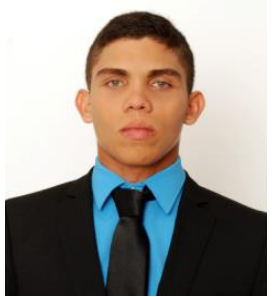

Andres Solano-Escorcia is currently pursuing a Bachelor's Degree in Electronic Engineering at Universidad de la Costa on full scholarship. Andres is an IEEE member and also of the IEEE Communications Society. His research interests include telecommunications, early warning systems, and fault prediction in induction motors.

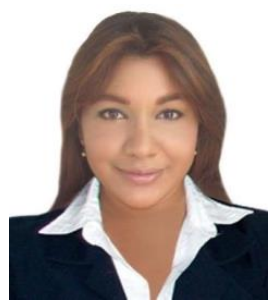

Lilia Rosa Ortega González is currently pursuing a Bachelor's Degree in Electronic Engineering at Universidad de la Costa on full scholarship. Her research interests include systems automation, IoT systems, Industry 4.0, electrical and electronic engineering education, and mechatronic automation design and integration. Currently linked as an instructor for the industrial automation network of the National Learning Service SENA and an independent contractor in the industrial automation and instrumentation sector.

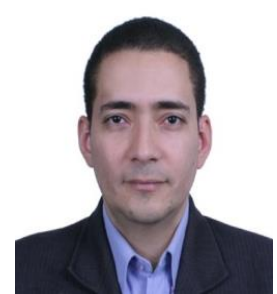

Ronald Zamora-Musa is a Research Professor of Engineering at the "Universidad Cooperativa de Colombia" in Barrancabermeja, Santander. His research covers innovation and new technology; he is interested in renewable energy, IT applications, and collaborative and immersive environments. He is a candidate for a Ph.D. in Engineering with MSc Engineering, and he is an Electronics and Telecommunications Engineer. 